\title{
Stem anatomy of Rhipsalis (Cactaceae) and its relevance for taxonomy
}

\author{
Alice Calvente $\cdot$ Regina H. P. Andreata \\ Ricardo C. Vieira
}

Published online: 14 November 2008

(C) Springer-Verlag 2008

\begin{abstract}
Several species of the genus Rhipsalis (Cactaceae) are extremely important as ornamentals and are endangered in their natural habitat. However, only a few studies have addressed its taxonomy, morphology (including anatomy), phylogeny and evolutionary history. Consequently, the limited knowledge of the genus coupled with the problematic delimitation of species had led to problems in the identification of taxa. In the current work six species of Rhipsalis, $R$. cereoides, R. elliptica, $R$. grandiflora, $R$. paradoxa, $R$. pentaptera and $R$. teres were studied to evaluate the relevance of anatomical characters for the taxonomy of the genus. An anatomical characterization of the primary structure of the stem of Rhipsalis is provided highlighting the differences between species. Features of the stem epidermis are found to discriminate
\end{abstract}

An incorrect version of this article was published earlier. The correct version is given here. The online version of the originally published article can be found at http://dx.doi.org/10.1007/s00606-008-0052-9.

A. Calvente $(\bowtie)$

Laboratório de Sistemática Vegetal,

Dep. de Botânica, IB, Universidade de São Paulo,

Rua do Matão 277, CEP: 05508-090 São Paulo, Brazil

e-mail: acalvente@ib.usp.br; acalvente@gmail.com

R. H. P. Andreata

Laboratório de Taxonomia de Angiospermas,

Instituto de Ciências Biológicas e Ambientais,

Universidade Santa Úrsula, R. Fernando Ferrari 75,

Botafogo, CEP: 22231-040 Rio de Janeiro, RJ, Brazil

R. C. Vieira

Laboratório de Morfologia Vegetal, Instituto de Biociências, Universidade Federal do Rio de Janeiro, CCS-Bl. A,

Sala 108, Cidade Universitária, Ilha do Fundão,

CEP: 21941-590 Rio de Janeiro, RJ, Brazil best between species and therefore provide clear and useful characters for the separation of species.

Keywords Anatomy $\cdot$ Brazil $\cdot$ Cactaceae $\cdot$ Rhipsalis . Taxonomy

\section{Introduction}

The majority of cacti have succulent stems and inhabit dry or arid lands. However, approximately $10 \%$ of the species of the family are epiphytes in humid regions. These species belong to the subfamily Cactoideae and form two natural groups: the tribe Hylocereae and the tribe Rhipsalideae (Barthlott 1983; Nyffeler 2002). Rhipsalis is the largest genus in the tribe Rhipsalideae with 36 species distributed in five subgenera: Calamorhipsalis K.Schum. (three spp.), Epallagogonium K.Schum. (seven spp.), Erythrorhipsalis A.Berger (eight spp.), Phyllarthrorhipsalis Buxb. (12 spp.), and Rhipsalis (six spp.) (Barthlott and Taylor 1995; Hunt 1999). The majority of species that belong to this genus ( $83 \%$ or 29 spp.) are endemic to Brazil, with several species presenting very restricted distribution ranges within the country.

Even though the various species of Rhipsalis are extremely important as ornamentals and are very endangered in their natural habitat, only few studies have addressed its taxonomy, morphology (including anatomy), phylogeny and evolutionary history (Barthlott 1983; Barthlott and Taylor 1995). Consequently, the limited knowledge of the genus and lack of adequate descriptions associated with identification keys, coupled with the problematic delimitation of species had led to problems in the identification of taxa within the genus (Calvente et al. 2005). Given the current degree of taxonomic uncertainty in the genus, 
detailed studies that could help on the species' circumscriptions are urgently needed.

The anatomy of the cactus family has been carefully studied and Boke (1964, 1968), Gibson (1973), Gibson and Nobel (1986), Gibson and Horak (1978), Loza-Cornejo and Terrazas (2003), Mauseth and Plemons-Rodriguez (1995, 1997, 1998), Mauseth et al. (1995) and Terrazas and Mauseth (2002) provided important references on this matter. Terrazas and Arias (2003) produced a complete review about the stem anatomy of the subfamily Cactoideae where they emphasized the great relevance of the anatomical characters for the study of the taxonomy and evolution of this subfamily. Anatomical studies within Rhipsalis were produced in the wider context of the family with few species analyzed (Eggli 1984; Gibson 1973; Mauseth and Plemons-Rodriguez 1998) or inside the tribe Rhipsalideae in the work of Hartl et al. (2003).

In the current work six species of Rhipsalis Gaertn.: $R$. cereoides (Backeb. and Voll.) Backeb., R. elliptica G.A. Lindberg ex K.Schum., $R$. grandiflora Haw., $R$. paradoxa (Salm-Dyck ex Pfeiff.) Salm-Dyck, $R$. pentaptera Pfeiff. ex A.Dietr. and $R$. teres (Vell.) Steudel were studied to evaluate the relevance of anatomical characters for the taxonomy of the genus. An anatomical characterization of the primary structure of the stem of Rhipsalis is provided highlighting the differences between species.

\section{Materials and methods}

The species studied are representatives of three of the five subgenera of Rhipsalis recognized in Barthlott and Taylor (1995): Rhipsalis (R. grandiflora and R. teres), Epallagogonium ( $R$. paradoxa and $R$. pentaptera) and Phyllarthrorhipsalis ( $R$. cereoides and $R$. elliptica). The specimens used for this study were collected in areas of the Atlantic Forest of the Rio de Janeiro State in Brazil. The minimum of two and the maximum of five specimens of each species were analyzed using available material, since these are endangered species (Calvente et al. 2005; Table 1). The middle third of the basal stem segments were fixed in FAA 70 (formalin-acetic acid-ethanol; Ruzin 1999) immediately after collection. After $24 \mathrm{~h}$, the material was stored in a solution of equal parts of ethanol, glycerin and $\mathrm{H}_{2} \mathrm{O}$.

Transverse sections were taken by free hand, clarified by sodium hypochlorite, stained with Safranin and Astra blue (Bukatsch 1972), dehydrated through an ethanol series and mounted in Canada balsam. The epidermis was dissociated through immersion in the Jeffrey solution (nitric acidchromic acid, Johansen 1940) for $24 \mathrm{~h}$ and then mounted according to the same procedure described for transverse sections. The number of stomata per area $\left(\mathrm{mm}^{2}\right)$ was determined through the arithmetic mean of 25 microscope fields, each one corresponding to a $1 \mathrm{~mm}^{2}$. The classification of stomata followed Wilkinson (1979).

Sections of fresh living material were used to make histochemical tests. The cuticle and cutinized cell walls were identified using Sudan IV and the starch using lugol (Johansen 1940). Sections were embedded in 10\% lead acetate for 6 min, washed with $\mathrm{H}_{2} \mathrm{O}$ and stained with methylene blue for testing for the presence of cellulosic mucilage (Dop and Gautié 1928).

\section{Results}

Rhipsalis Gaertn.

\section{Epidermis}

Uniseriate, building an even surface with cells arranged at the same level in Rhipsalis cereoides and R. elliptica or uniseriate to biseriate, building a crenate surface in $R$. grandiflora and $R$. paradoxa, and a crenulate surface in $R$. pentaptera and $R$. teres (Fig. 1a-f). Rhipsalis grandiflora, $R$. paradoxa and $R$. pentaptera have stomata located in depressions (sunken) and in Rhipsalis teres, $R$. cereoides and $R$. elliptica the stomata are not located in the depressions (Fig. 1a-f). The crenate surface in $R$. paradoxa epidermis is formed by the presence of stomata sunken in depressions while in $R$. teres the crenulate surface is formed by the regular arrangement of ordinary epidermal cells (Fig. 1d, f). In $R$. grandiflora and $R$. pentaptera the crenate surface of the former and crenulate surface of the latter are formed both by the presence of sunken stomata and the regular arrangement of ordinary epidermal cells (Fig. 1c, e). In $R$. grandiflora however, the stomatal depressions are as deep as the regular epidermal notches while in $R$. pentaptera the stomatal depressions (deep depressions) surpass the level of the regular epidermal notches (shallow depressions, Fig. 1c, e).

The epidermal cells in all species are polygonal, with 4-6 sides in frontal view and square to rectangular in transverse section covered by a thick cuticle (Fig. 1a-1). The areolar region may contain pluricellular trichomes, scale leafs or spines but the other regions of the stem epidermis are glabrous (Fig. 1a-f).

In frontal view the epidermal depressions observed in transverse sections are arranged in different patterns. In $R$. grandiflora and $R$. teres the depressions are in the form of channels, however, in $R$. grandiflora these channels delimit groups of cells forming a reticulate pattern and in $R$. teres they have a longitudinal arrangement dividing the epidermis in parallel lanes of cells (Fig. 1i, 1). Channels between the ordinary epidermal cells are also found in 
Table 1 Voucher of specimens used in this study

\begin{tabular}{ll}
\hline Species & Voucher \\
\hline Rhipsalis cereoides & A.M.Calvente 71 (RUSU); A.A.Barros et al. 2302 (JBRJ) \\
Rhipsalis elliptica & A.M.Calvente and L.M.Versieux 96 (RUSU), 214, 350 (SPF) \\
Rhipsalis grandiflora & A.M.Calvente and L.M.Versieux 95, 118 (RUSU) \\
Rhipsalis paradoxa & A.M.Calvente and L.M.Versieux 116 (RUSU), \\
& L.Cardoso s/n (RUSU 14317) \\
Rhipsalis pentaptera & A.M.Calvente and L.M.Versieux 100, 113 (RUSU) \\
Rhipsalis teres & A.M.Calvente et al. 61 (RUSU), A.M.Calvente \\
& and L.M.Versieux 86, 91, 94 (RUSU), 255 (SPF)
\end{tabular}

Fig. 1 a-f Epidermis and hypodermis in transverse sections. $\mathbf{g}-\mathbf{l}$ Epidermis in frontal view, $\mathbf{m}-\mathbf{r}$ cortex and stele. a, g, q Rhipsalis cereoides. $\mathbf{b}, \mathbf{h}, \mathbf{p}, \mathbf{r}$ R. elliptica. $\mathbf{c}, \mathbf{i}, \mathbf{m}, \mathbf{o} R$. grandiflora. $\mathbf{d}, \mathbf{j} R$. paradoxa. $\mathbf{e}, \mathbf{k} R$. pentaptera. $\mathbf{f}$, $\mathbf{l}, \mathbf{n} R$. teres. I Mucilage cells or cavities. II Sclerenchyma
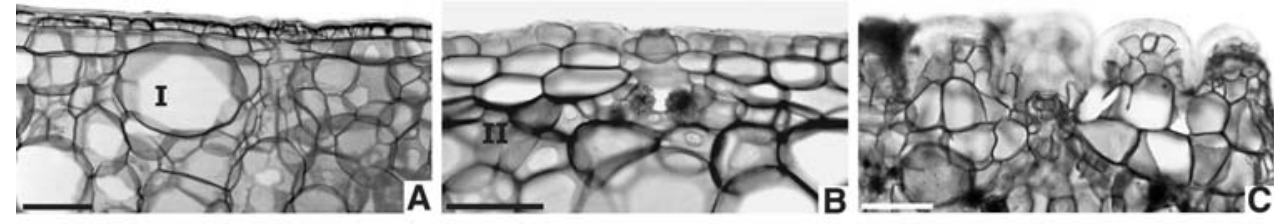
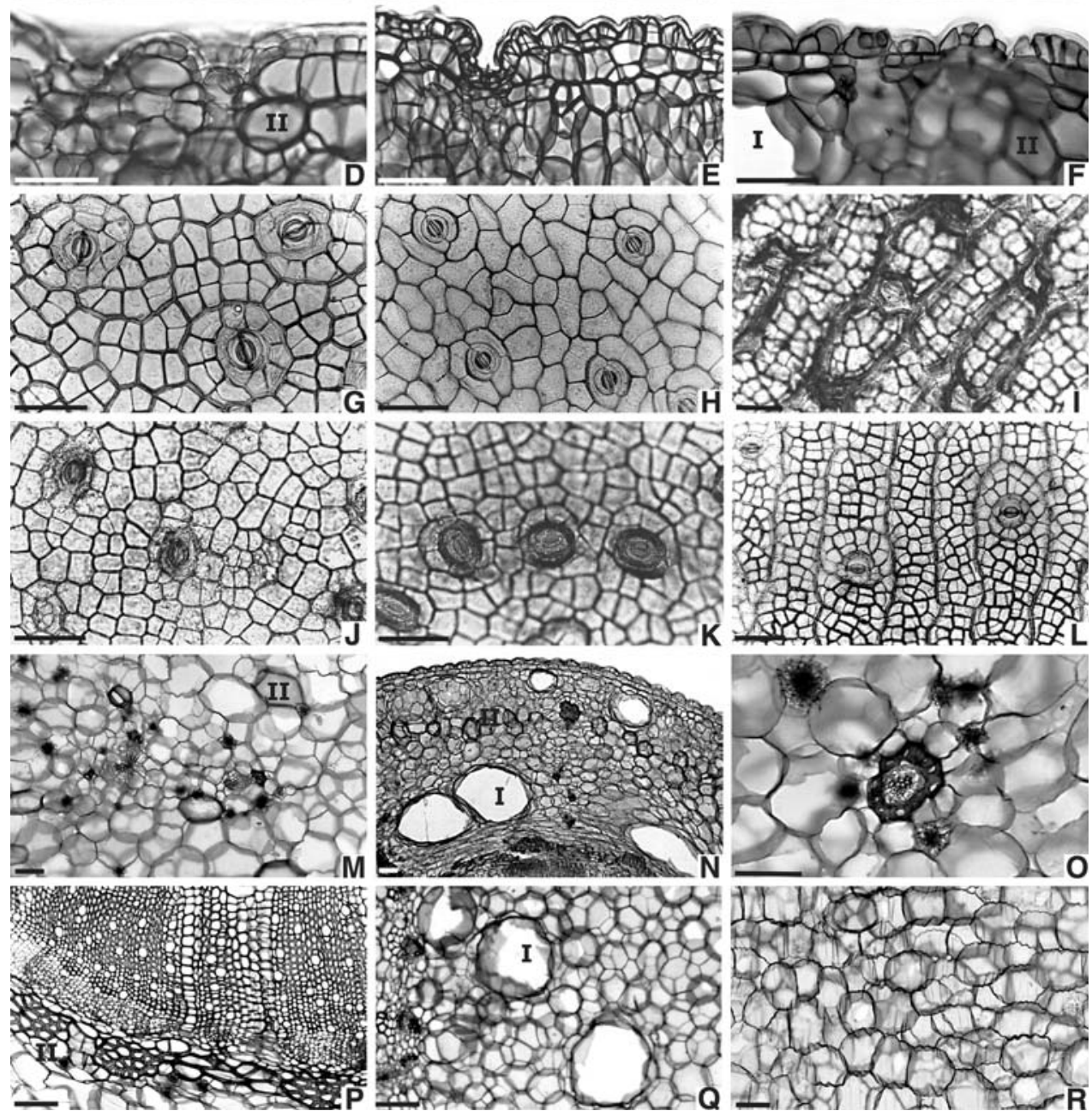

R. cereoides in frontal view. However, those channels are formed not by the presence of epidermal depressions but only by the thickening of the cuticule (Fig. 1a, g). The channels in $R$. cereoides epidermis delimit a circle or concentric circles around the stomata and irregular small groups of cells, which forms a reticulate pattern that is very different from the reticulate pattern observed in $R$. grandiflora (Fig. 1g, i). In both $R$. paradoxa and $R$. pentaptera the circular depressions observed in frontal view are formed by the presence of sunken stomata and, therefore 
have the same size of the stomata. In $R$. pentaptera other depressions formed by the regular arrangement of the epidermal cells were also observed in transverse section but those could not be detected to form channels in frontal view (Fig. 1e, k).

The stomata are paracytic or sometimes parallelocytic (Fig. 1g-1). The density of stomata is $13 \mathrm{st} . / \mathrm{mm}^{2}$ in $R$. elliptica and $R$. teres; $14 \mathrm{st} . / \mathrm{mm}^{2}$ in $R$. grandiflora, $17 \mathrm{st} . / \mathrm{mm}^{2}$ in $R$. cereoides, $18 \mathrm{st} . / \mathrm{mm}^{2}$ in $R$. paradoxa and $30 \mathrm{st} . / \mathrm{mm}^{2}$ in $R$. pentaptera.

\section{Cortex}

Interior to the epidermis is a hypodermis with 1-3 layers of chlorophyllous cells with irregular size and smaller than the cortical parenchyma cells. Thick walled hypodermal cells were observed only in $R$. teres and $R$. pentaptera. Crystalliferous idioblasts with druses are dispersed among hypodermal cells, especially around the substomatal chambers. The substomatal chambers exceed the hypodermis and may reach the cortical parenchyma (Fig. 1a-f).

The cortex is composed mainly of aquiferous parenchyma with more or less rounded cells of irregular size and shape (Fig. 1m, n). Chloroplasts occur through the entire cortex, but are more concentrated in the outer layers which are adjacent to the hypodermis. Crystalliferous idioblasts with druses are observed in the cortex and are more abundant in $R$. cereoides, $R$. elliptica and $R$. grandiflora and scarce in $R$. paradoxa (Table 2 ). A more or less continuous ring next to the hypodermis is built with the sclerenchyma (Fig. 1b, e, n). Isolated and scattered sclerenchyma is found throughout the inner and middle areas of the cortex, what is more frequent in $R$. grandiflora and rare in $R$. cereoides, $R$. pentaptera and $R$. teres (Fig. $1 \mathrm{~m}$; Table 2).

Cellulosic mucilage cells are dispersed in the cortex of all species. Mucilage cavities occur in all species but $R$. elliptica and $R$. grandiflora, and they are conspicuous and abundant in $R$. teres and $R$. cereoides (Fig. 1a, b; Table 2).

The cortical vascular bundles are collateral with clusters of fibers next to the phloem (Fig. 1m). A fiber sheath involving all the cortical vascular bundle may occur (Fig. 10).

\section{Stele}

The vascular system comprises collateral bundles that build a circular shape in $R$. grandiflora, $R$. paradoxa e $R$. teres; an elliptical shape in $R$. elliptica; a quadrangular or circular shape in $R$. cereoides and a pentagonal, quadrangular or rarely circular shape in $R$. pentaptera
(Table 2). A ring around the stele is formed by the sclerenchyma (Fig. 1p).

The pith is parenchymatous with some cells having a starch content. Sclerified parenchyma cells and crystalliferous idioblasts with druses occur scattered in the pith (Table 2). Mucilage cavities are found in the medullary tissue of $R$. cereoides, $R$. pentaptera and R. teres (Fig. 1q; Table 2).

\section{Discussion}

The present study has shown that most of the features of the anatomy of Rhipsalis support the anatomical patterns found in Cactaceae. The mostly uniseriate epidermis with thin walled cells covered by a thick hydrophobic cuticle, the chlorophyllous hypodermis with many druses, the parenchymatous tissue specialized in photosynthesis and water storage and the presence of cortical bundles are the main features previously described for Cactaceae (Terrazas and Mauseth 2002) that are here observed in the Rhipsalis species studied.

Terrazas and Arias (2003) highlight the importance of the epidermis as a source of anatomical diagnostic characters for the subfamily Cactoideae. This is corroborated here since all Rhipsalis species studied can be distinguished through epidermal characters. For example, $R$. grandiflora and forms of $R$. teres can be very similar vegetatively, what can make the identification difficult, but using epidermal characters these species are easily separated. Moreover, the pattern formed by the depressions in the epidermis together with the stomata arrangement was shown to be very useful for the separation of all the studied species and $R$. cereoides, $R$. grandiflora, $R$. pentaptera and $R$. teres are particularly distinguished by the unique combination of these features (Table 2). The epidermal characters here described were found to be constant among all the specimens of each species and, therefore, are used as species characters.

The stomata arrangement when analyzed solely distinguishes two groups of species. The first one is composed of $R$. cereoides, $R$. elliptica and $R$. teres that show an absence of sunken stomata. The second group is composed by $R$. grandiflora, $R$. pentaptera and $R$. paradoxa that show sunken stomata. Rhipsalis cereoides and $R$. elliptica both have non-sunken stomata and belong to the same subgenus Phyllarthrorhipsalis. The same applies to $R$. pentaptera and $R$. paradoxa that have sunken stomata and that belong to the subgenus Epallagogonium. Rhipsalis grandiflora and $R$. teres. However, belong to the subgenus Rhipsalis but show sunken and not sunken stomata, respectively.

The sunken stomata are an adaptation to xeric conditions, and the distribution of this character among the 


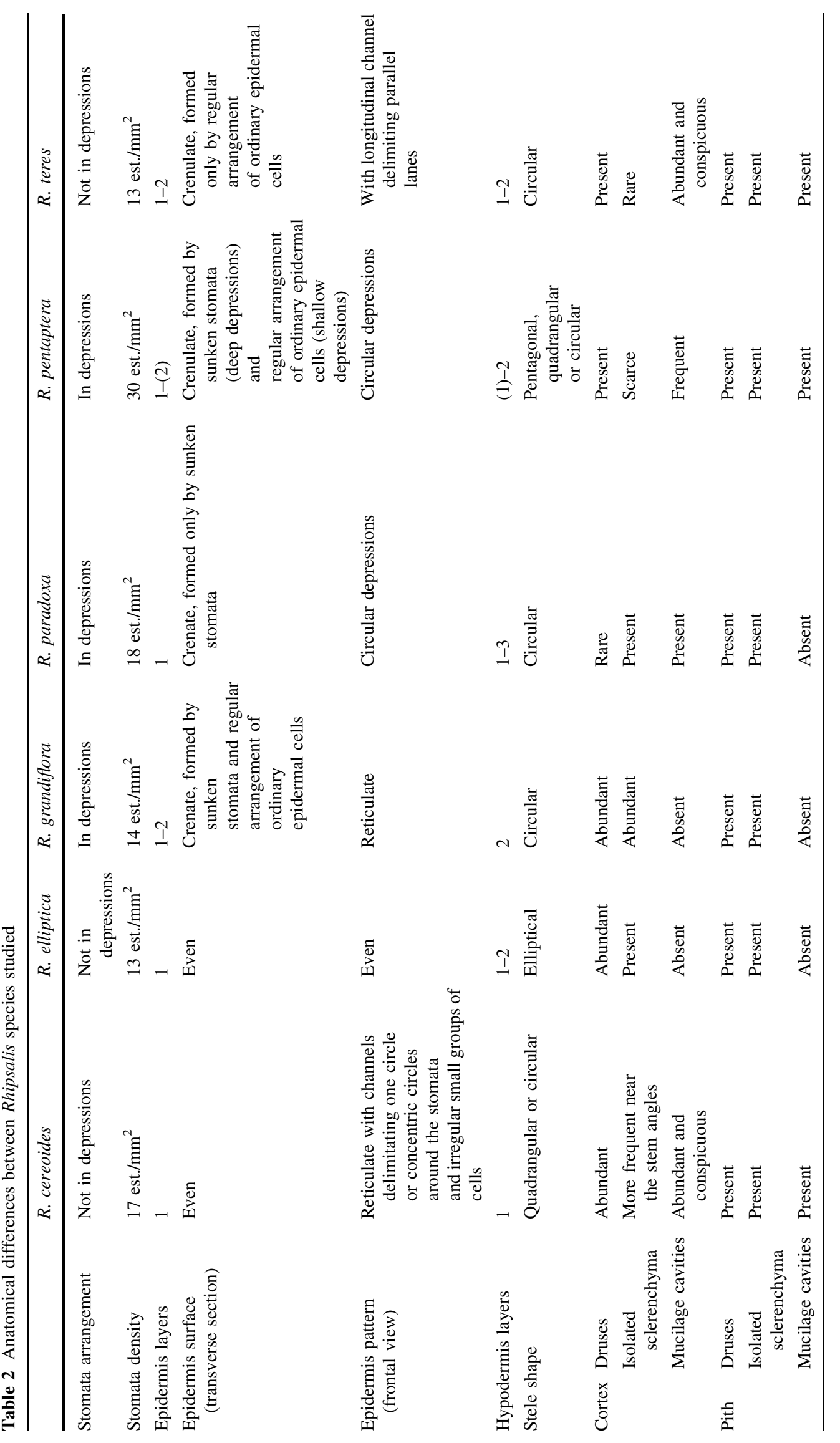


species suggest that it can have an interesting evolutionary history in the group, especially because all the species inhabit the dense and humid Atlantic forest suffering similar environmental conditions, except $R$. cereoides that inhabits the open and sunny rocky outcrops. A complete anatomical survey throughout the genus together with a reconstructed phylogeny for this group would provide further insights.

The occurrence of depressions and channels in the epidermis surface, despite the presence of sunken stomata also distinguishes two groups. The first one consists of $R$. grandiflora, $R$. pentaptera and $R$. teres that show the presence of depressions formed only by the regular arrangement of epidermal cells. The second group comprises $R$. grandiflora and $R$. teres that show the depressions associated with thickenings of the cuticle forming conspicuous channels in the epidermis. The placement of $R$. cereoides in this group is problematic since this species shows conspicuous channels in the epidermis in frontal view. However, in transverse section all epidermal cells occur in the same level and those channels are not composed of depressions but instead, of only thickenings of the cuticle. The occurrence of channels is also correlated with an adaptation to xeric conditions, but an analysis of the evolution of this character in this group should clearly follow a careful investigation since it can have distinct origins, it can be formed by epidermal depressions or by the thickening of the cuticle. The presence of depressions formed by the regular arrangement of ordinary epidermal cells, however, are considered a good taxonomic character because they are formed when one cells divides unequally, in different levels, producing clusters of epidermal cells (Terrazas and Mauseth 2002; Terrazas and Arias 2003).

The values of stomata density found in this study agree with the numbers related for the Cactaceae family, which are $20-80 \mathrm{st} . / \mathrm{mm}^{2}$ and is considered low compared to what is found in the leafs of other groups of plants (Terrazas and Mauseth 2002). The type of stomata previously observed for the subfamily Cactoideae is of the parallelocytic type (Terrazas and Arias 2003). However, in the present study the paracytic type was found more frequently among all the taxa. Also, the presence of a chlorenchymatous palisade parenchyma was previously observed for the Cactoideae species (Terrazas and Arias 2003). However, none of the studied Rhipsalis taxa have a palisade parenchyma.

Despite the fact that some of the characters seen in the cortex such as the presence of mucilage cavities, druses and isolated sclerenchyma are different among the taxa, they are mostly not constant among the specimens and not clear enough to be used solely as diagnostic characters (Table 2). Nevertheless, when used in combination they can be significant. The same was observed by Terrazas and Arias (2003) who found no taxonomical informative characters in the fundamental tissue of the Cactoideae cortex, but stated that the high frequency of mucilage cavities and channels in the cortex can be useful for the separation of specific or intraspecific taxa which is confirmed here in the case of $R$. cereoides and $R$. teres (Table 2).

In the stele some characteristics can be useful altogether for the separation of species, such as the stele shape (Table 2). On the contrary, the ring around the stele formed by the sclerenchyma and the parenchymatous pith with starch content, scattered druses and sclerenchyma are homogeneous characteristics among the taxa. Despite the Rhipsalis species being epiphytes not presenting conspicuous wood, further studies are being developed with the aim to describe and evaluate the evolutive importance of the secondary vascular structure in Rhipsalis. Even so, previous studies within Cactaceae and the subfamily Cactoideae have shown that the wood is homogeneous and does not provide characters to be used in species level taxonomy (Terrazas and Arias 2003; Mauseth and Plemons-Rodriguez 1998).

Many of the anatomical characteristics observed in the studied species are typical of xerophytic plants, what is expected since it is known that the typical stem of the Cactaceae has two main functions associated with xeric adaptations, the photosynthesis and the water accumulation (Gibson and Nobel 1986). However, instead of occurring in deserts as typical cacti, the Rhipsalis species occupy more mesic environments: the tropical forests. Therefore, the xeric adaptations shown by those species may have favored the occupation of habitats that are more subjected to the water stress inside the forests, as the epiphytic and rocky outcrop habitats. Examples of these xeric adaptations are the presence of druses that can affect the penetration of solar irradiation to the interior of the plant and the accumulation of hydrophilic mucilage that can facilitate the storage of water (Gibson and Nobel 1986). Moreover, it was observed in all Rhipsalis species studied that certain regions of the medium and internal cortex could behave like the collapsible parenchyma described by Mauseth (1995), but in a much less conspicuous manner as he observed in the species of Bolivicereus, Borzicactus, Cleistocactus, Espostoa, Gymnocalycium, Haageocereus, Loxanthocereus and Jasminocereus (Fig. 1r). These collapsible parenchyma cells have more flexible and elastic walls that allow more variation in the degree of hydration of the plant without causing cell damage or death.

In conclusion, the present anatomical studies with Rhipsalis taxa revealed some important characters that can be used for the separation of the species. The most informative among them are in the epidermis, such as the position of the stomata and the pattern exhibited by the epidermal cells and depressions. This study is promising 
and the sampling is being broadened among the genus and the tribe Rhipsalideae for a more detailed analysis of the anatomical variance and its implications towards the evolution of the group.

Acknowledgments The authors thank Ana Joffily, Carlos Marques, Danielle Domingues, Nathasha Carvalho and Rodrigo Léo for help during the development of this research; Teresa Terrazas for the suggestions about the anatomical procedures and for kindly providing copies of her papers; and Leonardo Versieux, Marcelo Pace, Mariane Souza, Louis Ronse De Craene and one anonymous reviewer for suggestions in the manuscript. This research was supported by the Coordenação de Aperfeiçoamento de Pessoal de Nível Superior (Capes) and by the Conselho Nacional de Pesquisas (CNPq) grants for the first and second authors, respectively and is part of the M.Sc. dissertation of the first author presented to the Programa de Pósgraduação em Ciências Biológicas (Botânica), Museu Nacional/UFRJ in 2005 .

\section{References}

Barthlott W (1983) Biogeography and evolution in neo and paleotropical Rhipsalinae (Cactaceae). In: Kubitzki K (ed) Dispersal and distribution: an international symposium, Sonderband des Naturwissenschaftlichen Vereins in Hamburg, vol 7, pp 241-248

Barthlott W, Taylor NP (1995) Notes towards a monograph of Rhipsalideae (Cactaceae). Bradleya 13:43-79

Boke NH (1964) The Cactus gynoecium: a new interpretation. Amer J Bot 51(6):598-610

Boke NH (1968) Structure and development of the flower and fruit of Pereskia diaz-romeroana. Amer J Bot 55(10):1254-1260

Bukatsch F (1972) Bemerkungen zur Doppelfärbung AstrablauSafranin. Mikrokosmos 61(8):255

Calvente AM, Freitas MF, Andreata RHP (2005) Listagem, distribuição geográfica e conservação das Cactaceae no Estado do Rio de Janeiro. Rodriguésia 56(87):141-162

Dop P, Gautié A (1928) Manuél de technique botanique, 2 edn. J. Lamarre, Paris

Eggli U (1984) Stomatal types of Cactaceae. Pl Syst Evol 146:197214

Gibson AC (1973) Comparative anatomy of secondary xylem in Cactoideae (Cactaceae). Biotropica 5(1):29-65
Gibson AC, Horak KE (1978) Systematic anatomy and phylogeny of Mexican columnar Cacti. Ann Missouri Bot Gard 65(4):999-1057

Gibson AC, Nobel PS (1986) The Cactus primer. Harvard University Press, Cambridge

Hartl WP, Barbier B, Klapper H, Müller P, Barthlott W (2003) Dimorphism of calcium oxalate crystals in stem tissues of Rhipsalideae (Cactaceae) - a contribution to the systematics and taxonomy of the tribe. Bot Jahrb 124(3):287-302

Hunt D (comp) (1999) CITES Cactaceae checklist, 2 edn. Royal Botanical Gardens Kew and International Organization for Succulent Plant Study (IOS), UK

Johansen DA (1940) Plant microtechnique. Mc Graw-Hill, New York

Loza-Cornejo S, Terrazas T (2003) Epidermal and hypodermal characteristics in Northican Cactoideae (Cactaceae). J Pl Res 116:27-35

Mauseth JD (1995) Collapsible water-storage cells in cacti. Bull Torrey Bot Club 122:145-151

Mauseth JD, Plemons-Rodriguez BJ (1995) Developmentally variable, polymorphic woods in Cacti. Amer J Bot 82(10):11991205

Mauseth JD, Plemons-Rodriguez BJ (1997) Presence of paratracheal water storage tissue does not alter vessel characters in cactus wood. Amer J Bot 84(6):815-822

Mauseth JD, Plemons-Rodriguez BJ (1998) Evolution of extreme xeromorphic characters in wood: a study of nine evolutionary lines in Cactaceae. Amer J Bot 85(2):209-218

Mauseth JD, Uozumi Y, Plemons BJ, Landrum JV (1995) Structural and systematics of an unusual tracheid type in cacti. J Pl Res 108:517-526

Nyffeler R (2002) Phylogenetic relationships in the cactus family (Cactaceae) based on evidence from $\operatorname{trn} \mathrm{K} / m a t \mathrm{~K}$ and $\operatorname{trn} \mathrm{L}-\operatorname{trn} \mathrm{F}$ sequences. Amer J Bot 89:312-326

Ruzin SE (1999) Plant microtechnique and microscopy. Oxford University Press, New York

Terrazas T, Arias S (2003) Comparative stem anatomy in the subfamily Cactoideae. Bot Rev 68(4):444-473

Terrazas T, Mauseth JD (2002) Shoot anatomy and morphology. In: Nobel PS (ed) Cacti: biology and uses. University of California Press, Berkley, pp 23-40

Wilkinson HP (1979) Stomata. In: Metcalfe CR, Chalk L (eds) Anatomy of the dicotyledons, vol 1, 2 edn. Clarendon Press, Oxford 